\title{
A HIGH-FIDELITY ARTIFICIAL AIRPORT ENVIRONMENT FOR SESAR APOC VALIDATION EXPERIMENTS
}

Florian Piekert, Nils Carstengerdes, Sebastian Schier, Reiner Suikat ${ }^{1}$ and Alan Marsden ${ }^{2}$

\section{ABSTRACT}

Europe's SESAR Program develops a wide range of solutions to increase the performance of the Air Traffic System. At airport level, the Airport Operations Center (APOC) is expected to provide the most benefit in adverse weather conditions, being the ultimate communication platform to pursue the Total Airport Management (TAM) Collaborative Decision Making Process. It will increase mutual and common situation awareness and allows the joint definition and implementation of the operational strategy.

The assessment of APOC benefits in a live airport environment is rather limited and requires implementation and "right" weather and traffic situations. This work argues for validation trials in high fidelity artificial airport environments as a more reliable and less costly alternative which allows comparison between operations before and after implementation of new solutions. Based on requirements provided by SESAR concept documentation and from live operations this work presents an approach for such a high fidelity artificial environment.

\section{KEYWORDS}

TAM; APOC; Validation; Human-in-the-Loop; Simulation Environment; SESAR

Corresponding Author: Florian Piekert

${ }^{1}$ DLR German Aerospace Center, Institute of Flight Guidance, Lilienthalplatz 7, 38108

Braunschweig, Germany, \{Florian.Piekert|Nils.Carstengerdes|Sebastian.Schier|Reiner.Suikat\}@DLR.DE, Tel +49-531295-3010 / Fax +49-531-295-2899

2 EUROCONTROL Experimental Center, Centre de Bois des Bordes BP15, 91222

Brétigny/Orge Cedex, France Alan.Marsden@EUROCONTROL.int 


\section{INTRODUCTION}

The SESAR (Single European Sky ATM Research) program is one of the most ambitious research and development projects ever launched by the European Community. The program is the technological and operational dimension of the Single European Sky (SES) initiative to meet future capacity and safety needs (European Commission, 2004, 2013; European Parliament \& European Council, 2004), in compatibility to the US initiative NextGen (Brooker, 2008; Federal Aviation Authority \& SESAR Joint Undertaking, 2014) and Japan's CARATS (Study Group for the Future Air Traffic Systems, 2010).

To coordinate and concentrate all relevant research and development efforts in the Community, the SESAR Joint Undertaking was founded by the European Commission and EUROCONTROL (European Council, 2007, 2008). Corresponding to the size and scale of the SESAR Program, a number of priority business needs (cf. SESAR Joint Undertaking, 2013, page 2) encompassing all of the ATM partners have been identified, referred to as 'SESAR Solutions'. These solutions are structured in a way as to ensure that their deployment will lead to benefits for all of the stakeholders across the ATM domain.

The validation of the different elements comprising each solution is structured around the so-called 'SESAR Release' process. Each Release comprises a number of validation exercises designed to prove the maturity of the individual building blocks of the overall SESAR concept and, as a result, their readiness for deployment.

Within the 'Airport Integration and Throughput' priority business area, a major work thread (Operational Focus Area - OFA 05.01.01) is focusing on the issue of Airport Operations Management (AOM) and among its research scope the development and validation of an Airport Operations Plan (AOP) and Airport Operations Center (APOC) for managing airport operations in nominal, adverse and/or exceptional operating conditions is addressed.

The SESAR AOM Concept (Bogers et al., 2015a, 2015b) builds upon the European Airport Collaborative Decision Making (A-CDM) concept (EUROCONTROL, 2013a). The concept will be scalable in order to permit its implementation across the broadest possible spectrum of Airport environments present in Europe and it is articulated around four services (Marsden, 2014). The are the Steer Airport Performance, Monitor Airport Performance, Manage Airport Performance and the Perform Post-Operations Analysis service.

The validation of these four services associated to the Airport Operations Management concept is being performed by the SESAR partners with a focus on so-called maturity levels V1 through to V3, following the standardized European Operational Concept Validation Methodology (E-OCVM; EUROCONTROL, 2010). The work to date has comprised the iterative Journal of Air Transport Studies, Volume 8, Issue 1, 2017 
elaboration of the SESAR AOM concept by the definition of operational requirements captured in the form of an Operational Services and Environment Description (OSED; Bogers et al., 2015a, 2015b) and integrating specific operational processes such as the management of demand and capacity imbalances. This realization was subjected to V1 and V2 validation activities and the results have been used to further refine the OSED.

What still is missing is a benefit assessment of the concept and the associated prototypes within a dynamic and realistic environment.

\section{LITERATURE REVIEW}

Validation is employed in a wide range of disciplines, e.g. in statistics, medical products, car manufacturing industry and in air traffic management research (e.g. Carstengerdes, Jipp, Piekert, Reinholz, \& Suikat, 2012). All validation endeavours have the common goal to provide a fit for purpose identification of differing complexity for the proposed aspect under consideration. In SESAR it is important to use validation as a means of quantifying the benefits or demonstration that the anticipated benefits have been achieved by the concept and prototypical implementation.

E-OCVM foresees eight phases, starting from V0 to V7. Whereas phase V0 and V1 of the E-OCVM Concept Lifecycle Model define the air traffic management needs, the scope of the concept under test and the possible operational and technical solutions, phase V2 addresses feasibility, acceptance and operability issues. The major advantage of the E-OCVM methodology lies in the opportunity of assessments and quick reactions to potential showstoppers at early concept stages. With each phase the validation scope and the realism of the validation activities are evolving. The more mature a concept is, the more ecologically valid (Brewer, 2000) the validation activity has to become regarding the operational context.

The term "lifecycle" indicates that concept development and validation are tightly coupled in view of the fact that validation activities are supporting the refinement of the concept which - in turn - will be validated again until the transition criteria to the next validation phase are achieved. In the next phase, this process is starting again.

Coming from the V2 questions dealing with feasibility aspects, V3 is concerned with the preindustrial development and integration. Validation activities in this phase are therefore related to the assessment of operational benefits of the concept under test. The concept and supporting enablers like prototypes, roles, procedures and responsibilities, and associated 
human performance aspects are evaluated together in order to clearly identify costs and benefits associated with the proposed solution to the identified ATM need.

Finally, concepts should be stable after this phase and ready for a transition into an operational environment (V4: industrialization), followed by deployment (V5), operations (V6), and decommissioning (V7).

It should be clear from this description that every phase (V1 to V3) has its own set of appropriate validation techniques, tools and methods, starting with literature studies, modeland data based approaches, gaming or fast-time simulations and ending with real-time simulations, shadow-mode and even live trials.

The most straight-forward approach to assess the benefit of new procedures and technologies is the comparison of situations, where the application or implementation of these innovations has not yet occurred, with situations where the new procedures are applied or the technologies have been operationally implemented. Depending on the individual enhancement each procedure or technology is expected to provide, the induced effect may vary greatly and may even vary from situation to situation.

Regular operations, without external disturbances, appear to be well manageable and most probably can still benefit from innovations. But most of the potential of some innovative solutions in airport management was designed to manifest in situations that forces limitations onto the well-established operational processes. A major proportion of these bottleneck situations are caused by weather phenomena (EUROCONTROL, 2013b; Lau, Forster, Tafferner, Dzikus, \& Gollnick, 2011; United States Department of Transportation / Bureau of Transportation Statistics, 2015), affecting various operating areas. Generally assumed, the intensity of the bottleneck situation is dependent on the severity of the weather phenomenon.

V3 validation can be supported by a wide range of techniques, with live trials being considered the culmination. The above indicated ideal solution environment apparently is an airport in live operations where, over an extended period of time, qualifying metrics have been measured prior and after APOC implementation and adjustment of procedures was completed. But considering the intended target situation, the crux is the availability of these situations when required. It appears unreasonable to start the implementation of innovations into a live environment and then wait for these situations to occur only to conduct benefit assessments as a decision support whether to implement these systems or not. Additionally, in cases where the implementation costs are high or have significant risks associated to them, the implementation in the live environment may be pursued only as a second step. In 
those cases, applicable to the innovations addressed in this work, the first step is the benefit assessment in a live-like, but artificial environment that allows controlling of all parameters.

Consequently, the environment that qualifies for a V3 APOC validation has to offer a dynamic representation of the world typically encountered at an airport and the possibility of hosting the innovative prototype systems supporting the concept and operators.

These aspects can be expressed as requirements. The validation environment that consists of the artificial airport environment, including the baseline support systems, and the novel support systems that support the new AOM concept elements, need to cope with this set of requirements. Concerning the airport environment, the requirements in most cases are a reflection of the live operational environment transcribed into specific IT terms. The AOM concept covers requirements concerning its new conceptual functions and procedures. It does not directly provide requirements for validation environments, as the concept itself was created for a live operational environment. A thorough analysis of the concept's requirements has to be performed and the appropriate requirements have to be transferred into the individual exercises' validation plans (e.g. Carstengerdes et al., 2015). For example, such requirements can be grouped into requirements concerning the validation environment, operational procedures and functional aspects for the support systems. Examples are provided below.

\begin{tabular}{|c|c|}
\hline Type & Example \\
\hline Environment & $\begin{array}{l}\text { "It is assumed that the airport simulated in the validation exercises is at least a primary node, i.e. a medium sized } \\
\text { airport with a limited hub function and intercontinental P2P connections (e.g. Lyon Saint-Exupéry, Nice, Budapest, } \\
\text { Warsaw, Athens etc.)" (Carstengerdes et al., 2015, p. 34). }\end{array}$ \\
\hline Procedure & $\begin{array}{l}\text { "It is assumed that the airport simulated in the reference scenario has implemented the A-CDM Information Sharing } \\
\text { element of the A-CDM concept. In particular, it is assumed that this airport is equipped with an A-CDM Information } \\
\text { Sharing Platform and similarly that the A-CDM concept elements of variable taxi-time and milestone monitoring are } \\
\text { all implemented" (Carstengerdes et al., 2015, p. 31). }\end{array}$ \\
\hline Procedure & $\begin{array}{l}\text { "The APOC supervisor or responsible stakeholder (depending on the severity level A, B, C, D) shall update the } \\
\text { overall impact message in the system (AOP)" (Bogers et al., 2015a, p. 235). }\end{array}$ \\
\hline Functional & $\begin{array}{l}\text { "Each warning / alert from airport performance monitoring shall lead to the instantiation of an overall impact } \\
\text { message. This OIM will be indicated to the responsible stakeholder determined in advance" (Bogers et al., 2015a, p. } \\
\text { 234). }\end{array}$ \\
\hline
\end{tabular}

Table 1: Examples for different types of requirements

Theoretically, every air transportation network and airport process and procedure can be modelled and then simulated with highest level of detail and degree of realism. Highly sophisticated models may, however, not always be required, or the real world data is not available in sufficient quality or quantity. A taxonomy of simulations and application of various modelling types and detail levels is provided in Haßa (2016) and further examples 
are given in Odoni et al. (1997) and De Prins, Ledesma, Mulder, and van Paassen (2008). It is therefore evident, that an appropriate scaling of the process simulation that adheres to the requirements of V3 assessments has to occur.

Additionally, as explained above, exercises require specific weather information to unlock the potential of these innovations. This information has to be provided not only to the human operators (who will act as stakeholder representatives), but as well to the driving simulators and the APOC support systems. All will use this weather information in their area of work. The simulators will have to dynamically provide model driven reactions in the process chains and the APOC support systems will assist the operators in assessing the severity of the impact. The human operators who additionally judge by their experience what is presented to them will identify the implied consequences on airport operations. This approach will allow control of the most important experimental parameters. These focus around the timely distribution of weather or other disruptive events which are affecting the airport processes, and the air traffic demand and its density distribution (e.g. arrival and departure ratios).

In the remaining sections the above argumentation will be exemplified by an approach for conducting a V3 real-time Human-in-the-Loop (HitL) validation exercise (identified as SESAR EXE-06.03.01-VP-757). In this exercise it was necessary to not only identify the already documented requirements, but additionally to construct the necessary simulation requirements.

\section{THEORETICAL CONTRIBUTION}

The requirements build a framework of needs that has to be fulfilled by four pillars of this exercise. These are a) the industrial prototypes that provide the new functionality and procedure support, b) the physical environment where operators will be working jointly, $c$ ) the simulators that simulate reality and d) user interfaces as the means of interaction between operators and the support systems. These four pillars will be explained in more detail in the following sub sections.

\section{THE INDUSTRIAL PROTOTYPES}

INDRA is the industrial partner in this validation exercise and has developed the Systems Under Test (SUT) prototypes. Due to INDRA's business needs and intended target customers, their prototypes are designed to connect to operational airport systems or to 
systems of the local air navigation service provider (ANSP). Therefore, the simulation environment has to provide similar interfaces and data of comparable quality. The SESAR Airport Operations Management concept (OFA 05.01.01 OSED; Bogers et al., 2015a, 2015b) envisages that with the deployment of APOC processes at an airport, A-CDM processes become established automatically, as these present the foundation of this collaborative airport management approach. Further, when the APOC concept and its support tools are deployed, it is assumed that airport data sharing will be conducted via System Wide Information Management (SWIM; Petrovsky et al., 2012).

The AINS prototype (developed within SESAR Work Package (WP) 12.06.09 - "Integration of CDM into SWIM") is a SWIM gateway system, feeding the Airport Operations Plan (AOP) with local A-CDM information and providing information back into the SWIM. The ASDI prototype (SESAR WP 12.06.07 - "AMAN, SMAN and DMAN fully integrated into CDM processes") presents the bridge to the local ANSP, thus providing ANSP related planning information to the AOP. The AOP prototype (SESAR WP 12.06.02) is implementing the Airport Operations Plan and adequate mechanisms and procedures to manage all aspects relevant for the concept. The majority of airport related data will be directly provided by the Airport Operational Data Base (AODB), which is a part of the A-CDM simulator, to the AOP, which acts as the data core of the APOC processes. The interfaces between the simulation environment and the prototypes are implemented following state-of-the-art techniques (e.g. web service mechanisms). Together with the APAMS prototype (SESAR WP 12.07.03 "Airport Performance Assessment Monitoring System"), the AOP implements the Steer Airport Performance, Monitor Airport Performance and Manage Airport Performance services as outlined by the conceptual approach (Bogers et al., 2015a, 2015b).

\section{THE AIRPORT CONTROL CENTER SIMULATOR}

The ACCES (Spies et al., 2008; Suikat, Kaltenhäuser, Hampe, Timmermann, \& Weber, 2010) is an infrastructure component of DLR's Air Traffic Validation Center (Kaltenhäuser, 2015). It consists of a server room housing the computers running the simulation as well as the industrial prototypes and a large multi-purpose room that can accommodate operators for human-in-the-loop exercises, the validation supervisor, the simulation control team and exercise observer teams. An additional room to host operational level operator working positions is also provided adjacent. The main operator room provides flexibility for different validation setups, operator working positions can be freely rearranged on ground level as exercises require, e.g. to support research on the optimal seating arrangement to optimize 
stakeholder communication. The simulation control team and the validation supervisor are located on an elevated platform hosting the simulation control system interfaces, opposite to an optional large video projection screen. The current arrangement of operator working and control team positions is depicted in the photograph below (figure 1), which includes a schematic 2D diagram of the overall arrangement. Currently, there are six operator working positions installed, in a hexagon arrangement. For positioning two operators in front of a single working position another chair can be added, the tables and available spacing provide enough room. Observers to exercises can be positioned either next to or behind the working positions, or on the simulation control team's platform.

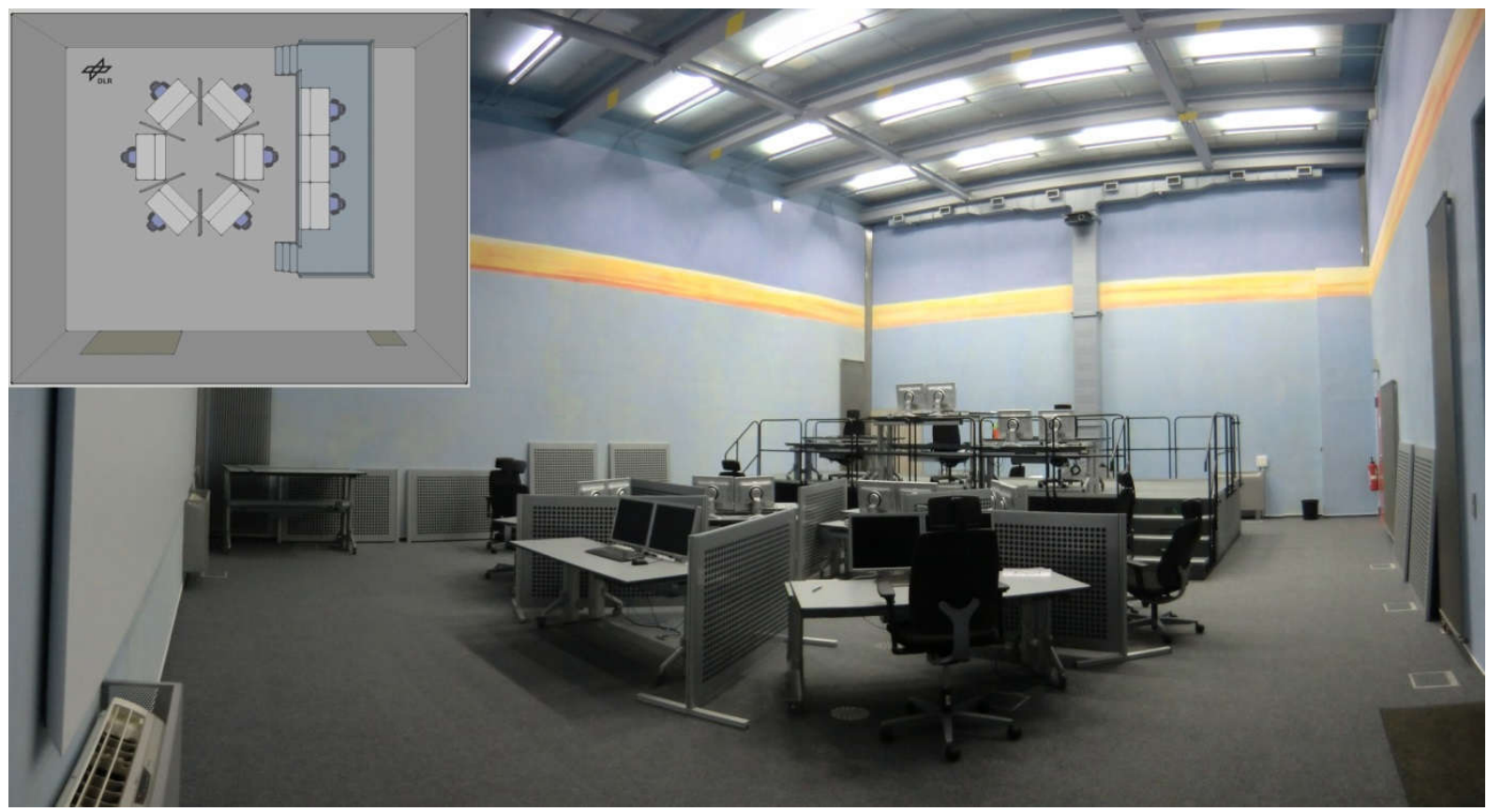

Figure 1: ACCES Control Room Layout (long shot and 2D layout, operator positions in front)

\section{THE SIMULATION ENVIRONMENT}

The technical simulation system is based on a combination of simulators described by Spies et al. (2008), refined in Suikat and Deutschmann (2008) and further elaborated in Suikat (2012). The approach taken for this V3 assessment does not require all of those combined specialized simulators with their full functionality.

The central components to be used is an Airport Collaborative Decision Making (A-CDM) simulation (Schier, Timmermann, \& Pett, 2016). This simulation models a flights' progress over time and sets the necessary event milestones required for the airport management. As for some phases of the flights a simple process model is not detailed enough, additional 
simulation models were added to conduct a joint simulation and cover all aspects with sufficient detail level.

TAMODES (Kügler \& Reichmuth, 2012), which features a complete turnaround process simulation, was redeveloped and its core turnaround simulator engine was integrated into the A-CDM simulation engine. The most important passenger process milestones (A-CDM milestone \#11 "Boarding starts" and A-CDM Milestone \#12 "Aircraft Ready") are thus provided by functionality within the A-CDM simulator, while a full passenger/landside simulation is not required.

The air traffic simulator NARSIM (developed by NLR; NARSIM, 2013) simulates aircraft movements in final approach, on runways, taxiways and the apron. Based on the total energy model and the base of aircraft data (Nuic, 2014) these phases are calculated in high accuracy and can therefore give a more realistic impression than the calculations of the ACDM milestone simulation.

Support vehicles that are required for the turnaround processes are not addressed in detail in this exercise. The A-CDM simulator will use appropriate turnaround times matching to the simulated scenario airport.

The validation does not require a direct connection to the Network Manager (exchange of information with the Network Operations Plan, NOP); nevertheless there exists the need to obtain information from the NOP (e.g. A-CDM milestone \#3 "Take off from outstation" or A-CDM milestone \#4 "Local radar update", which can be understood as a Flight Update Message (FUM) and Slot Assignments). All of these will be created by the simulator, while Departure Planning Information (DPI) and Slot Requests will be submitted by the tools. DPIs are not relevant for the assessment. Further, it is assumed that the Network Manager will actively support solution implementation in bottleneck situations. This implies that the simulation will accept the requested slots as they are. Although this is a deviation from reality to some degree, the overall assessment does not suffer from this as this approach will be the same for both, the so-called reference and solution runs (which are described below in section 8). 

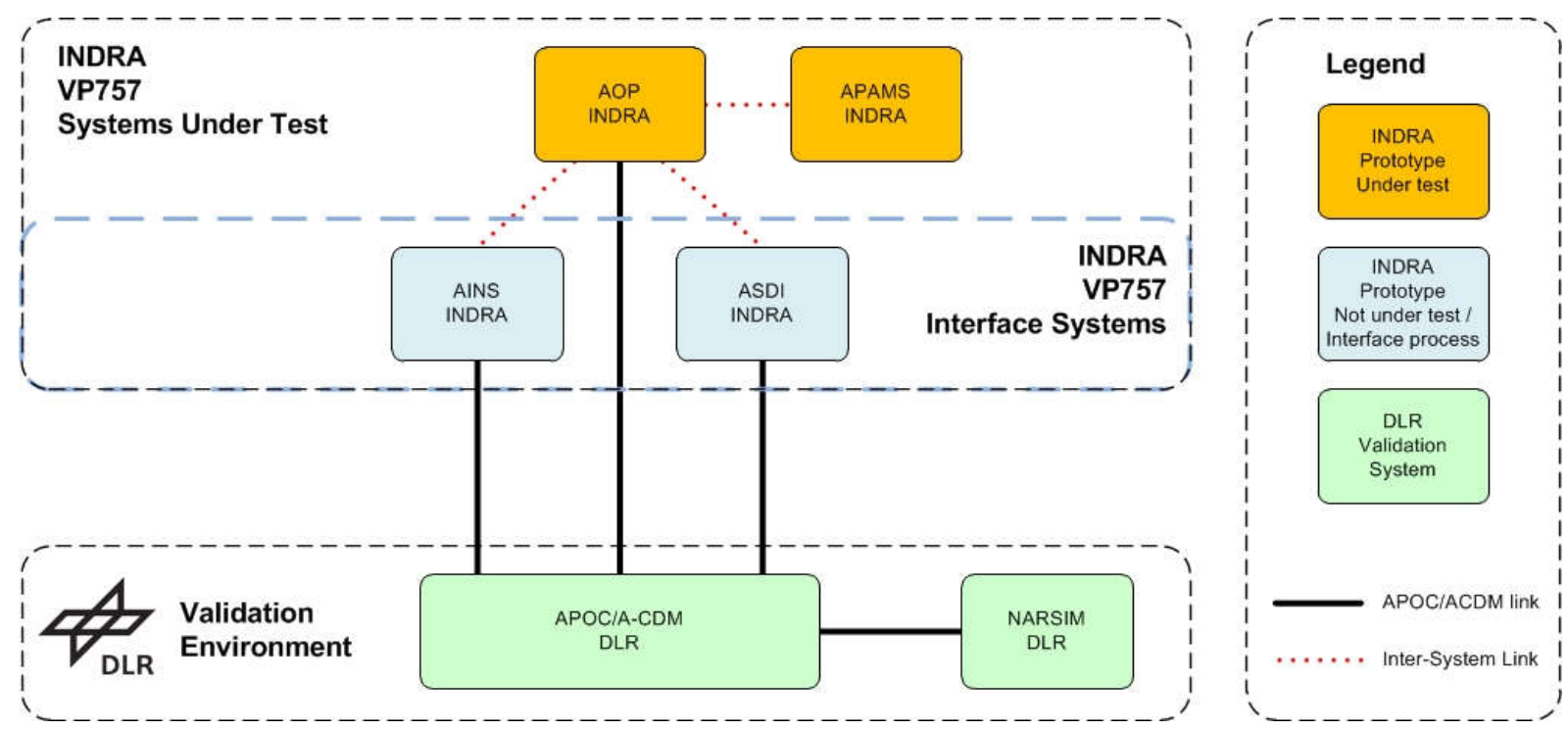

Figure 2: EXE-6.3.1-VP-757 Solution Situation Technical Setup of Prototypes and Simulators

Figure 2 depicts the technical system setup of EXE-6.3.1-VP-757. It shows various systems, DLR's validation environment featuring the combined simulators, INDRA's prototypes that represent the Systems Under Test and auxiliary support systems acting as interface systems. The solid lines depict the uni- and bi-directional connections between the simulators and INDRA's industrial prototypes used in the validation exercises, implementing the APOC/A-CDM link between the systems. The dotted lines represent the inter-prototype connection of INDRA's systems.

\section{OPERATOR USER INTERFACES}

AOP, APAMS and the A-CDM simulation provide Human Machine Interfaces (HMI) to the exercise operators. While the industrial solutions offer sophisticated functionality, the A-CDM HMI supplies the basic functionality that is required for these V3 exercises (Schier, Pett, Mohr, \& Yeo, 2016). Assuming that the implementation of operational decisions is conducted on the operational level (e.g. via the airline Flight Operations or Hub Control Centre), the A-CDM HMI is used for these implementations (e.g. setting of the runway capacities by the local ANSP, adjustment of a TOBT (Target Off-Block Time), cancellation of a flight or a slot request) and for the actions of the airport actors.

The industrial HMIs are used to interact with the three above mentioned APOC services. When the stakeholders involved in the exercise agree on process planning aspects, these are stored in the AOP. Due to the bi-directional link between the AOP and the simulation environment, these new parameters are presented to the simulation. These then are used by 
the simulation models to derive the implementation result, dynamically altering the future development of the traffic, metrics and the course of the exercise.

The simulation additionally provides a set of control HMIs to the technical supervisor and simulation control staff.

\section{THE APPROACH TO APOC VALIDATION}

The aforementioned APOC solution will be evaluated using the human-in-the-loop real time simulation technique in the above mentioned environment. The purpose of the proposed validation activity is to demonstrate that the developed SESAR APOC concept (including prototypes supporting the operators in performance monitoring, assessment and management as described above) leads to improved situation awareness and - owing to the collaborative approach to decision making - to a quicker recovery to normal operations and an improved overall airport performance (relating to different key performance indicators like departure and arrival delay, punctuality, usage of available apron and runway capacity). Especially, this should hold true for situations with adverse conditions where a highly collaborative environment will facilitate an improved decision making. Furthermore, the validation will assess if the APOC concept and environment provides an enriched data availability to generate post-operation analysis reports which can be used for the generation of solution support for the APOC operators in future adverse conditions.

Therefore, the key elements of the APOC concept for validation are:

- Situational Awareness of current and predicted airport performance through the AOP data content and alert messages,

- Overall Airport Performance Monitoring and Alerting,

- Deviation Impact Assessment,

- Collaborative Decision Making for performance optimization, and

- Enriched data availability for post-operations analyses.

\section{APOC AVAILABILITY}

The impact of the presence of an APOC (so-called "solution scenario") will be validated against airport operations without APOC and support tools (so-called "reference scenario"). As explained above, A-CDM is considered as the current standard and state-of-the-art for airport management, and therefore considered as reference. Accordingly, the management 
functionalities provided in the two scenarios differ from each other. In the reference scenario the operators will only be provided with their individual "local systems" which deliver input to and allow interaction with the A-CDM platform and consequently the AODB. The APOC and its associated support tools are not provided, consequently not allowing tool supported performance monitoring and no provision of performance alerts to all stakeholders at the same time and no facilitation of the collaborative decision making process.

Three different exercises with different impact severity levels and key drivers like the possibility to anticipate the constrained situation or the location of the disruption (airside or landside) have been chosen based on actual operational constraints, which are typical of airport operations. These scenarios have been successfully used in former OFA 05.01.01 validation trials (Goni Modrego et al., 2015; Marsden et al., 2014) and will be adapted regarding severity and possible course of action to fit to the validation questions at hand. As a result, six runs (three different exercises, each executed twice, once as reference and once as solution scenario) will be performed with operational experts.

To be more specific regarding the content of the three exercises, in validation exercise \#1 an airport faces a constrained situation whereby an external disruption coupled with the execution of planned works on the apron will lead to significant ground congestion. Validation exercise \#2 deals with a situation where the airport is faced with a heavy thunderstorm whilst a light thunderstorm was forecasted. This adverse condition affects the operation of all airport stakeholders. In validation exercise \#3, a disruption in passenger processes will take place due to an incident at the security control. These three situations have to be resolved with (solution) and without (reference) the APOC and its industrial support tools.

Using this approach, the benefit of the APOC concept will be shown in different performance degraded situations with different impact on each stakeholder and with different management options to mitigate the situation. This and in conjunction with the realistic APOC simulation environment will result in a more accurate assessment of the overall benefit of the APOC as a platform to pursue and enable the Total Airport Management (TAM) CDM (Günther et al., 2006; Spies et al., 2008).

\section{THE REFERENCE SETUP}

Figure 2 and figure 3 depict the logical setup of stakeholders and operating work places for the reference and solution scenario approaches. In the reference setup, as figure 2 shows, 
there are three airlines (Airspace User - AU) present, addressing different AU business models/mode of operations; hub and low cost operator and the third represents all others including cargo operations. Two representatives from the operation level share a work place for each $\mathrm{AU}$, representing e.g. the functions of a "Strategic and CDM Manager" and "Slot Manager" (the function denominators may vary from $A U$ to $A U$ in reality). Together they decide and implement operational decisions on aircraft movements and problem solution strategies. These two are representatives of a typically larger operational group usually involved in the AUs' processes. The local ANSP has a single representative, combining the Airport Tower Supervisor role and incorporating the Clearance Delivery Controller operational level role in these exercises. No direct communication to controllers is required as this is simulated by the simulation environment and no additional back office support is required for the exercise. The Airport Operator again has two representatives; the Airport Operator and the Stand and Gate planning role. They are locally grouped with their two working positions. All stakeholder companies have access to the local A-CDM system (HMI) only, an HMI that they share between their representatives. The airport Stand Planner additionally has access to a Stand and Gate Management system (powered by the simulation environment). The two stakeholder representatives can directly communicate face to face. The inter-stakeholder communication is limited to the use of a messaging system or phone only. No direct face to face communication is foreseen, to reflect the reality at most airports nowadays (with the exception of airports already using a centralized multi-stakeholder facility).

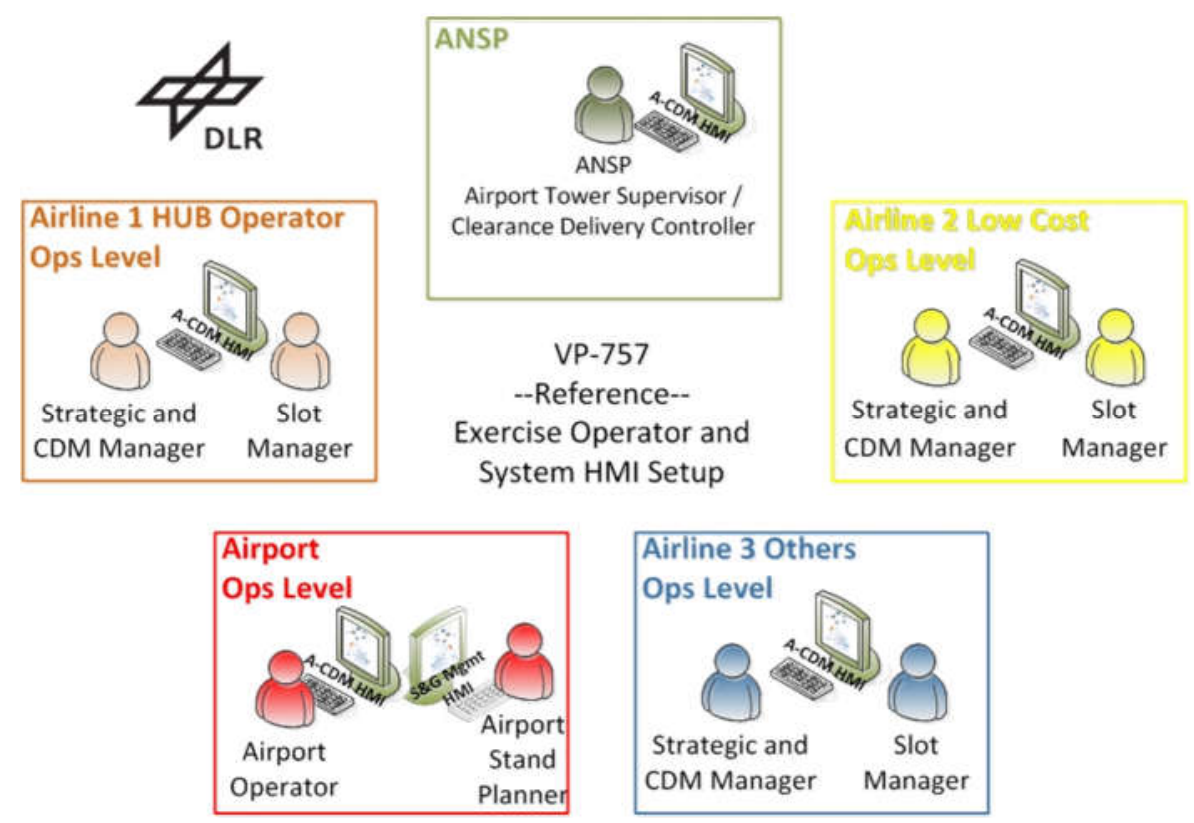

Figure 3: EXE-6.3.1-VP-757 Reference Situation Operators and HMIs 
Due to the non-necessity of a direct link to the Network Manager (European Commission, 2004, 2005, 2010, 2011a, 2011b)/NOP, there is no Network Manager Representative (in reality this stakeholder may be represented by the Flow Manager Role at an airport) and no corresponding working position in either scenario setup. Since the three airspace user companies represent $100 \%$ of all traffic and aircraft handling decisions, the presence of a ground handler representative is omitted similarly.

\section{THE SOLUTION SETUP}

In contrast to the reference setup is the solution setup, which is depicted in figure 3 . All management level representatives will be situated in a central APOC, the operational level representatives will be located outside the APOC, providing a degree of realism since the stakeholders' operation centres are not part of the APOC. The three Airspace Users each have a single management level representative and an associated working position in the APOC and another operational level representative in a back office environment (representing e.g. the Flight Dispatch or Hub Control Centre). Again, the operational level representatives will be responsible for the operational implementation of decisions for the airline. The local Air Navigation Service Provider (ANSP) will have the same representative as in the reference setup in the APOC, maybe not replacing the Tower Supervisor, but with an entirely new role defined. Again, there is no back office support for the local ANSP in this exercise setup. The Airport Operator will act as the APOC supervisor, being authorized to decide in decision making stalls and representing the goals of the airport. The supervisor is supported by an operational level representative outside the APOC, including the role of the Stand Planner as before. 


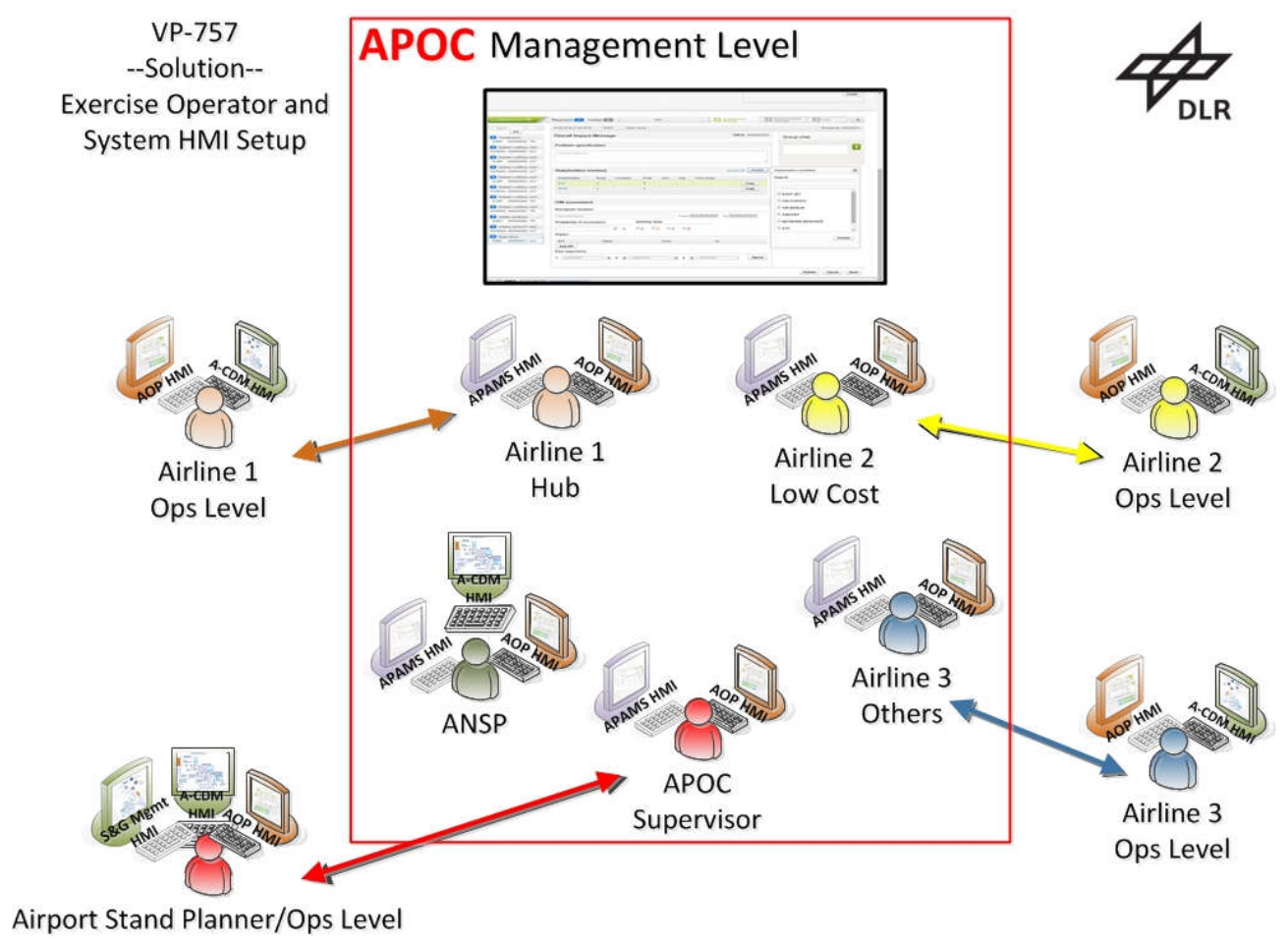

Figure 4: EXE-6.3.1-VP-757 Solution Situation Operators and HMIs

The APOC will provide a centralized video wall installation, where the APOC supervisor's APAMS HMI will be displayed. This video wall is expected to increase the situational awareness of the stakeholders' representatives and supports the efficiency of the decision making processes. The representatives in the APOC have access to HMIs of APAMS and the AOP, the local ANSP representative additionally has access to the local A-CDM HMI (since he still needs to implement his operational decisions for ease of simulation setup). The back office representatives have access to the AOP and A-CDM HMIs. The airlines' views are filtered though, to allow access to their own flights only while the airport back office sees the full picture for all flights. Additionally, the Stand and Gate Management System access lies with the airport back office representative. All operational level decisions and implementations are conducted by these representatives outside the APOC, while the management decisions are taken by the agents in the APOC. The agents can communicate with their back offices via phone or the messaging system. Inside the APOC all representatives have a direct face to face inter-stakeholder communication and may use the phone and the messaging system. 
By implementing this setup it now is possible to conduct a V3 APOC assessment for the first time, providing a suitable dynamic environment for systems and operators, and fulfilling external and ecological validity criteria.

\section{SUMMARY AND CONCLUSIONS}

The next steps that will be taken on the way to the conclusion of this important validation goal include a variety of technical and support actions.

The industrial prototypes need to be integrated into the airport simulation environment after their development has concluded and the simulators have been enhanced to satisfy the interface requirements. Following this technical milestone, a thorough verification phase will be conducted, ensuring the reliability, consistency and interoperability of all technical components. This includes the execution of test runs with operators (not necessarily operational experts) to assess the correct operation of the system HMIs. These experiments will additionally be used to adjust prototype parameters where necessary and help to scope the specific scenario configuration that will then be used for the validation exercise runs.

Parallel to the technical actions, the preparation of the scenarios will be started, including the adaptation and definition of use cases based on the OSED that define the work flow of the operators in the APOC. The scenarios include definitions of events and the time of their occurrence, forming the storybook that will be used by the simulation control team to trigger those events as these would happen unforeseen on a real day of operations.

The test runs will be planned carefully, together with the real exercise schedule. Additional training test sessions with the operational expert personal will be conducted as part of the verification phase. This phase will be completed with the system acceptance test. The solution bundle referred to in this work is a part of the SESAR Release 5 cycle. Therefore, once the verification and preparatory actions have concluded, the "ready for validation" will be awarded through the SESAR System Engineering \#2 (SE\#2) Review.

Once the SE\#2 is passed, the previously invited subject matter experts conduct the previously scheduled set of validation exercises, which are expected to be completed within a week's duration, running multiple exercises per day. During the execution of the exercises the relevant data from the systems, the simulators and the human interactions are captured and adequately processed. This data then will be analysed by the validation team responsible for the validation exercise. Under the consultation of the industrial and the operational SESAR partners, the data will be evaluated and assessed against the pre-defined validation 
goals and corresponding success criteria, using the pre-defined metrics. A comprehensive validation report will finally conclude the validation.

With the successful completion of this validation activity, the SESAR APOC validation activities will be completed. The identified lessons learned and potential modifications derived from the assessment then will be used to provide input to a new edition 4 of the OSED and additionally may be included in the work program for SESAR 2020 (SESAR Joint Undertaking, 2014) which is expected to be launched at the end of 2016. By implementing the above mentioned requirements, the realistic and dynamic high-fidelity validation environment as described in this work offers the capabilities that are needed for this final SESAR APOC validation assessment. Furthermore, it closes the gap between pure laboratory experiments and live trials by offering flexibility concerning the required degree of fidelity and sophistication in order to deliver meaningful operational benefit assessments. The studies can be conducted in a scenario based approach using experimental designs, allowing control of confounding variables. The environment is ready to be used or can easily be adapted for future SESAR 2020 and Performance Based Airport Management (PBAM) APOC innovative research and validation assessments.

\section{ACKNOWLEDGEMENTS}

The adaptation of the ACCES to the needs of the SESAR validation exercises has been partially financed with SESAR Project 06.03.01 funds under "Specific Agreement No. 4, LOT 1 - Information Management, Implementing Framework Partnership Agreement, Ref. SJU/LC/0158-CTR" governed by the SESAR JU (2014-2016).

The authors would like to thank Felix Timmermann of DLR's Institute of Flight Guidance for the schematic 2D diagram of the ACCES layout and Carl Welman of NLR's AT division for the basis of the technical layout chart.

Further, the authors would like to express their gratitude towards the SESAR partners involved in the validation exercise for collaboratively deciding on and defining of all exercise related aspects.

\section{REFERENCES}

Bogers, H., Linde, M., Matas Sebatia, J. R., Álvarez Escotto, I., Martin Espinosa, J. I., Ciprián Tejero, B., . . . Ubeda Torres, J. A. (2015a). D16 - OFA 05.01.01 Consolidated OSED, Part 1. Retrieved from Brussels, Belgium: 
Bogers, H., Linde, M., Matas Sebatia, J. R., Álvarez Escotto, I., Martin Espinosa, J. I., Ciprián Tejero, B., . . . Ubeda Torres, J. A. (2015b). D16 - OFA 05.01.01 Consolidated OSED, Part 2. Retrieved from Brussels, Belgium:

Brewer, M. B. (2000). Handbook of Research Methods in Social and Personality Psychology (H. T. Reis \& C. M. Judd Eds.). Cambridge, USA: Cambridge University Press.

Brooker, P. (2008). SESAR and NextGen: Investing in new paradigms. Journal of Navigation, 61(2), 195-208. doi:Doi 10.1017/S0373463307004596

Carstengerdes, N., Jipp, M., Piekert, F., Reinholz, A., \& Suikat, R. (2012). Validation of the Total Airport Management Suite - Research Report (DLR IB 112-2012/35). Retrieved from Braunschweig, Germany: http://d-nb.info/1028431228/34

Carstengerdes, N., Papenfuss, A., Piekert, F., Rafidison, J.-P., Suikat, R., Welman, C., .. . Jimeno Cuenca, D. (2015). EXE-06.03.01-VP-757 Validation Plan. Retrieved from Brussels, Belgium:

De Prins, J., Ledesma, R. G., Mulder, M., \& van Paassen, M. M. R. (2008). Literature review of air traffic controller modeling for traffic simulations. Paper presented at the Digital Avionics Systems Conference, 2008. DASC 2008. IEEE/AIAA 27th. https://www.researchgate.net/publication/224357955 Literature review of air traffi c controller modeling for traffic simulations

EUROCONTROL. (2010). E-OCVM Version 3.0 Vol. 1. EUROCONTROL (Ed.) European Operational Concept Validation Methodology (pp. 76). Retrieved from http://www.eurocontrol.int/valfor/gallery/content/public/docs/EOCVM3\%20Vol\%20I\%20WebRelease.pdf

EUROCONTROL. (2013a). Airport CDM Implementation The Manual(pp. 359). Retrieved from http://www.eurocontrol.int/documents/airport-cdm-implementation-manualversion-4

EUROCONTROL. (2013b). CODA Digest - Annual 2012. Retrieved from Brussels, Belgium: http://www.eurocontrol.int/sites/default/files/content/documents/officialdocuments/facts-and-figures/coda-reports/CODA-Digests-2012/coda-digest-annual2012.pdf

REGULATION (EC) No 551/2004 OF THE EUROPEAN PARLIAMENT AND OF THE COUNCIL of 10 March 2004 on the organisation and use of the airspace in the single European sky (the airspace Regulation), 551/2004 C.F.R. (2004).

COMMISSION REGULATION (EU) No 2096/2005 of 20 December 2005 laying down common requirements for the provision of air navigation services, 2096/2005 C.F.R. (2005).

COMMISSION REGULATION (EU) No 691/2010 of 29 July 2010 laying down a performance scheme for air navigation services and network functions and amending Regulation (EC) No 2096/2005 laying down common requirements for the provision of air navigation services, 691/2010 C.F.R. (2010).

COMMISSION DECISION of 7.7.2011 on the nomination of the Network Manager for the air traffic management (ATM) network functions of the single European sky, (2011a).

COMMISSION REGULATION (EU) No 677/2011 of 7 July 2011 laying down detailed rules for the implementation of air traffic management (ATM) network functions and amending Regulation (EU) No 691/2010, 677/2011 C.F.R. (2011b).

European Commission. (2013). Accelerating the implementation of the Single European Sky (COM(2013) 408 final). Retrieved from Brussels, Belgium: ec.europa.eu/transport/modes/air/single_european_sky/doc/ses2plus/com(2013)408_ en.pdf

COUNCIL REGULATION (EC) No 219/2007 of 27 February 2007 on the establishment of a Joint Undertaking to develop the new generation European air traffic management system (SESAR), 219/2007 C.F.R. (2007).

COUNCIL REGULATION (EC) No 1361/2008 of 16 December 2008 amending Regulation (EC) No $219 / 2007$ on the establishment of a joint undertaking to develop the new 
generation European air traffic management system (SESAR), 1361/2008 C.F.R. (2008).

REGULATION (EC) No 549/2004 OF THE EUROPEAN PARLIAMENT AND THE COUNCIL of 10 March 2004 laying down the framework for the creation of the single European sky, 549/2004 C.F.R. (2004).

Federal Aviation Authority, \& SESAR Joint Undertaking. (2014). State of Harmonisation Document (978-92-9216-026-5). Retrieved from Luxemburg, Luxemburg:

http://www.sesarju.eu/sites/default/files/documents/reports/State-ofHarmonisation.pdf

Goni Modrego, E., Callejo Tamayo, E., Bots, A., Linde, M., Bogers, H., Steinkjer, J., . . . Marsden, A. (2015). Consolidated EXE-06-05-04-VP-013 Validation Report. Retrieved from Brussels, Belgium:

Günther, Y., Inard, A., Werther, B., Bonnier, M., Spies, G., Marsden, A., . . . Niederstraßer, H. (2006). Total Airport Management - Operational Concept \& Logical Architecture. Retrieved from Braunschweig, Germany: http://www.bs.dlr.de/tam/Dokuments/TAMOCD-public.pdf

$\mathrm{Haßa}, \mathrm{O}$. (2016). Eine anwendungsorientierte Einführung in ATM-Simulationen. Innovationen im Fokus, 1/2016, 12.

Kaltenhäuser, S. (2015). The Air Traffic Validation Center. Retrieved from http://www.dlr.de/fl/en/desktopdefault.aspx/tabid-1140/

Kügler, D., \& Reichmuth, J. (2012). Schlussbericht Vorhaben "TAMS - Total Airport Management Suite" (IB 112-2012/15). Retrieved from Braunschweig, Germany: http://www.tams.aero/documents/schlussberichte/IB 112-201215 TAMS Schlussbericht DLR v1.00 public.pdf

Lau, A., Forster, C., Tafferner, A., Dzikus, N., \& Gollnick, V. (2011). Assessment of a Convective Weather Nowcasting and Tracking Algorithm Based on Delay Reduction Potential at Munich Airport (Part I). Paper presented at the 11th AIAA Aviation Technology, Integration and Operations (ATIO) Conference, including the AIAA, Virginia Beach, VA, USA.

Marsden, A. (2014). Airport Operations Management. SESAR Factsheet, 6. Retrieved from https://www.eurocontrol.int/publications/sesar-factsheet-airport-operationsmanagement //

https://www.eurocontrol.int/sites/default/files/content/documents/sesar/sesarfactsheet-airport-operations-management.pdf

Marsden, A., Mongénie, O., Goni Modrego, E., Delain, O., Bots, A., Bourguignat, D., . . . Foetsch, S. (2014). EXE-06.05.04-VP-013 Validation Plan. Retrieved from Brussels, Belgium:

NARSIM. (2013). NARSIM - Human in the loop ATC simulations. Retrieved from https://www.narsim.org/

Nuic, A. (2014). USER MANUAL FOR THE BASE OF AIRCRAFT DATA (BADA) REVISION 3.12 Project $B A D A$ (pp. 106). Retrieved from

https://www.eurocontrol.int/sites/default/files/field tabs/content/documents/sesar/us er-manual-bada-3-12.pdf doi:EEC 14/04/24-44

Odoni, A. R., Bowman, J., Delahaye, D., Deyst, J. J., Feron, E., Hansman, R. J., . . . Simpson, R. W. (1997). Existing and Required Modeling Capabilities for Evaluating ATM Systems and Concepts. Retrieved from Boston, MA, USA: https://dspace.mit.edu/bitstream/handle/1721.1/96073/NASAAATT FinalReport.pdf?sequence $=1$

Petrovsky, A., Van Der Stricht, S., Cruellas, P., Janssens, D., Brochard, M., Roelants, E., . . . Lebars, Y. (2012). D40 - SWIM Concept of Operations (P08.01.01 D40). Retrieved from Brussels, Belgium: 
Schier, S., Pett, T., Mohr, O. K., \& Yeo, S. J. (2016). Design and Evaluation of User Interfaces for an Airport Management Simulation. Paper presented at the AIAA Aviation Modelling and Simulation Conference, Washington, D.C., USA.

Schier, S., Timmermann, F., \& Pett, T. (2016). AIRPORT MANAGEMENT IN THE BOX - $A$ HUMAN-IN-THE-LOOP SIMULATION FOR ACDM AND AIRPORT MANAGEMENT Paper presented at the Deutscher Luft- und Raumfahrt Kongress 2016, Braunschweig, Germany. http://elib.dlr.de/103619/

SESAR Joint Undertaking. (2013). SESAR Release 2 (SESAR_RELEASE_2013). Retrieved from Brussels, Belgium:

http://www.sesarju.eu/sites/default/files/documents/reports/sesar release result2 1 31007.pdf?issuusl=ignore

SESAR Joint Undertaking. (2014). SESAR 2020: developing the next generation of European Air Traffic Management. SESAR Factsheet, 2. Retrieved from http://www.sesarju.eu/newsroom/brochures-publications/sesar-2020-developingnext-generation-european-air-traffic

Spies, G., Piekert, F., Marsden, A., Suikat, R., Meier, C., \& Eriksen, P. (2008, 2008-09-14). Operational Concept for an Airport Operations Center to enable Total Airport Management. Paper presented at the 26th Congress of International Council of the Aeronautical Sciences (ICAS) 2008, Alaska, USA.

Study Group for the Future Air Traffic Systems. (2010). CARATS Collaborative Actions for Renovation of Air Traffic Systems - Long-term Vision for the Future Air Traffic Systems Changes to Intelligent Air Traffic Systems . Retrieved from http://www.mlit.go.jp/common/000128185.pdf

Suikat, R. (2012). TAMS Simulation Concept Document. Retrieved from Braunschweig, Germany: http://www.tams.aero/documents/konzeptdokumente/TAMS SCD v-1-00 public.pdf

Suikat, R., \& Deutschmann, A. (2008). Total Airport Simulation Supporting Research for Future Airport Management Concepts AIAA Modeling and Simulation Technologies Conference and Exhibit. Honolulu, Hawaii, USA: American Institute of Aeronautics and Astronautics.

Suikat, R., Kaltenhäuser, S., Hampe, J., Timmermann, F., \& Weber, B. (2010). ACCES - A Gaming and Simulation Platform for Advanced Airport Operations Concepts AIAA Modeling and Simulation Technologies Conference: American Institute of Aeronautics and Astronautics.

United States Department of Transportation / Bureau of Transportation Statistics. (2015). Airline On-Time Statistics and Delay Causes. Retrieved from http://www.transtats.bts.gov/OT Delay/OT DelayCause1.asp 